\title{
Human papillomavirus viral load in cervical intraepithelial neoplasia as a prognostic factor in a Mexican population
}

A.E. Bencomo-Álvarez ${ }^{1,2}$, I. Limones-Perches ${ }^{2}$, A.E. Suárez-Rincón ${ }^{3}$, L.J. Ramírez-Jirano ${ }^{2}$, E. Borrayo-Carbajal ${ }^{1}$, J. Sánchez-Corona ${ }^{2}$ and H. Montoya-Fuentes ${ }^{2}$

${ }^{1}$ Doctorado en Genética Humana, Centro Universitario de Ciencias de la Salud, Universidad de Guadalajara, Guadalajara, Jalisco, México

${ }^{2}$ División de Medicina Molecular, Centro de Investigación Biomédica de Occidente, Instituto Mexicano del Seguro Social, Guadalajara, Jalisco, México ${ }^{3}$ Unidad de Investigación en Colposcopia y Patología Cervical, Instituto Mexicano del Seguro Social, Guadalajara, Jalisco, México

Corresponding author: H. Montoya-Fuentes

E-mail: schlagzeugger@hotmail.com

Genet. Mol. Res. 11 (4): 4720-4727 (2012)

Received March 30, 2012

Accepted June 22, 2012

Published October 4, 2012

DOI http://dx.doi.org/10.4238/2012.October.4.2

\begin{abstract}
Persistent infection with human papillomavirus (HPV) has been recognized as the main etiological factor of morbimortality in cervical cancer. Several factors have been associated with the development of cervical disease, but viral load has recently been proposed as an indicator of cervical neoplasia. Therefore, a single measurement of viral load could be a suitable biomarker. We examined HPV viral load as a prognostic biomarker of cervical neoplasia. We used cervical scrapes to determine the total HPV viral load of 46 Mexican patients with various stages of cervical intraepithelial neoplasia (CIN) using hybrid capture assay coupled with a quantitative polymerase chain reaction method for cellularity estimation. Viral load values of CIN2 and CIN3 samples were compared with samples without cervical
\end{abstract}


pathology (WP); all values of viral load were normalized by number of cells analyzed. The analysis showed significant differences in viral load between CIN2 and WP samples $(\mathrm{P}=0.01)$ and between CIN3 and WP samples $(\mathrm{P}=0.02)$. By contrast, no significant difference was detected between viral loads in CIN2 and CIN3 samples. The results showed significant difference between viral loads in CIN2 and CIN3 samples and that in WP samples. HPV viral load was significantly different between patients with CIN2-CIN3 and those with WP and can be used as a predictor of lesions.

Key words: Human papillomavirus; Dysplasia prognosis factor; HPV viral load

\section{INTRODUCTION}

Persistent infection with human papillomavirus (HPV) is the major etiological factor of morbidity and mortality in cervical cancer and the second most frequent malignant tumor of women worldwide (Seaman et al., 2010). Infection with high-risk HPV (HR-HPV) is the key event in the development of cervical cancer and its precursor lesions, known as cervical intraepithelial neoplasia (CIN). HR-HPV types (including HPV-16 and -18) are associated with more than $99 \%$ of all cervical cancers as well as with high-grade CIN (CIN2-3) and abnormal Papanicolaou test (Pap) results. Low-risk HPV types are responsible for additional abnormal Pap test results and almost all cases of genital warts (Winer et al., 2003; Boulet et al., 2009; Hesselink et al., 2009; Seaman et al., 2010).

The involvement of several factors in the development and progression of cervical disease has been described, the main factors being HR-HPV and the constant burden of HPV, which is approximately 50-100 viral copies, inside the cell (McMurray et al., 2001; Javier and Butel, 2008). Recent studies have described viral load as an effective diagnostic and prognostic marker for CIN (Castle et al., 2005; Moberg et al., 2005; Lillo and Uberti-Foppa, 2006; Fiander et al., 2007; Boulet et al., 2009; Hesselink et al., 2009). On the spectrum of cervical disease, CIN2 and 3 are considered cervical cancer precursors. Several studies have consistently reported that the persistence of HR-HPV in the genital tract is necessary for the development and progression of cervical dysplastic lesions (Ho et al., 1995; Remmink et al., 1995; Nobbenhuis et al., 1999; Briolat et al., 2007; Xi et al., 2008; Sargent et al., 2010). Conversely, high-grade squamous intraepithelial lesions were shown to be unlikely to develop in HR-HPVnegative women in a 2-year follow-up cohort, and smears showed that mild or borderline cell atypia returns to normal (Nobbenhuis et al., 2001; Zielinski et al., 2001).

Because persistent HR-HPV infection is the major risk factor for cervical carcinoma and considering the sensitive and reproducible methods available for HR-HPV DNA, HRHPV status could be part of the screening and management of women at risk for progression to CIN2, CIN3, or worse (Briolat et al., 2007). However, the use of HPV testing combined with cervical cytology to detect cervical cancer or its precursors is still controversial and insufficient (Cain and Howett, 2000; Fiander et al., 2007; Boulet et al., 2009; Hesselink et al., 2009; Grce et al., 2010). Given the positive relationship between viral load and the likelihood of persistent HPV infection and the strong association between the latter and the risk of cervi- 
cal neoplasia, a single measurement of viral load in cervical specimens may be a suitable biomarker (Schlecht et al., 2003; Boulet et al., 2009). Studies have identified HPV viral load as a biomarker for cervical lesions in women and evaluated the predictive association of viral load and the incidence of cervical cancer precursors (Josefsson et al., 2000; Ylitalo et al., 2000; Clavel et al., 2001; Fiander et al., 2007; Boulet et al., 2009; Hesselink et al., 2009). Contrary to hepatitis $\mathrm{C}$ or human immunodeficiency virus viral load assessment, the interpretation of the measured load of HPV in cervical specimens is difficult owing to the variable exfoliated cell content of each sample, which depends on the resistance of the epithelium to abrasion and other physiological conditions. The controversial results of HPV viral load estimations may be explained by the lack of normalization with an externally validated method of the number of studied cells in the samples. In this study, we report a comparison of cell-normalized HPV viral loads of patients with a clinical diagnostic of CIN2 and CIN3 and patients without cervical pathology (WP).

\section{MATERIAL AND METHODS}

\section{Study population}

A cross-sectional survey was conducted at the dysplasia clinic of the Instituto Mexicano del Seguro Social Zone General Hospital 45. Women aged 18 years or older who had not had a hysterectomy and were not menstruating or pregnant at the time of the analysis were considered for this study. Conventional colposcopic examination and a structured questionnaire including socio-demographic status, sexual activity, history of sexually transmitted infection, obstetrical and gynecological history, and risk factors for cervical cancer were performed. The study was approved by the Local Ethics Committee.

\section{Clinical samples}

Cervical samples from 46 Mexican patients were collected in DNA collection devices (QIAGEN, Gaithersburg, MD, USA). The colposcopist collected a cervical scrape from each patient using a cytobrush and stored the samples for HPV testing with the DNA cervical samples. The cytology results were classified according to the Bethesda system (2001), and the histopathological analysis determined the grade of CIN. The samples were classified in CIN2, CIN3, and WP.

\section{Molecular analysis}

Cells were pelleted through centrifugation and resuspended in lysis buffer (10 $\mathrm{mM}$ Tris, $1 \mathrm{mM}$ ethylenediaminetetraacetic acid, $200 \mu \mathrm{g} / \mathrm{mL}$ proteinase $\mathrm{K}$ ) for a 12 -h digestion at $56^{\circ} \mathrm{C}$. Digestion was followed by the inactivation of proteinase $\mathrm{K}$ and a 10 -min incubation at $95^{\circ} \mathrm{C}$. Polymerase chain reaction (PCR) amplification [with consensus primers for the HPV-E1 open reading frame as reported by Mendizabal-Ruiz et al. (2009)] was performed to determine the positivity to HPV in each sample. HPV DNA detection was performed with a Hybrid Capture 2 System (HCIIS; Digene, Gaithersburg, MD, USA). All scrapes were analyzed for the global presence of the 13 most common HR-HPV types. Samples were classified as positive for HR- 
HPV DNA if the relative light unit (RLU) reading obtained from the luminometer was equal or greater than the mean value of a triplicate of positive controls supplied with the HCIIS kit.

HCIIS was used to determine the total viral number, and the interpretation for each result was presented in RLU values that were converted into a ratio to the cutoff value (1 pg/ $\mathrm{mL}$ ). Specimens with a ratio of $<1.00$ were considered to be negative, and those with a ratio of $\geq 1.00$ were considered to be positive because they contained at least $1 \mathrm{pg} / \mathrm{mL}$ HPV DNA, equivalent to 100,000 HPV copies/mL or 5000 HPV copies/assay (Sargent et al., 2010).

\section{Quantification of HPV viral load}

Because the addition of a known amount of DNA to each PCR is impractical for a large series of clinical samples, our approach included normalization for sample cellularity via a quantitative PCR melting curve of the human glyceraldehyde 3-phosphate dehydrogenase gene to obtain a number of cells per sample. The human glyceraldehyde 3-phosphate dehydrogenase gene DNA load was determined with real-time PCR assay on a LightCycler instrument (Roche Diagnostics, Mannheim, Germany) in separate reactions to quantify the number of HPV copies and the number of cells. The LightCycler assays and the primers and probes were from a LightCycler $\mathrm{t}(9 ; 22)$ quantification kit (Roche Molecular Biochemicals, Penzberg, Germany). The data were normalized using this formula:

$$
\text { Viral load }=\operatorname{antilog}[\log (R L U \times 5000) / \log (\text { total No. of cells })]
$$

\section{Statistical analysis}

Data analysis was conducted for medians and parametric and non-parametric tests for proportions. We also performed a mean test comparison for independent samples for each group. The Levene test was carried out to assess the equality of variance between samples. Subsequently, one-way analysis of variance was performed to identify differences between the variances of the groups. Finally, we used the Dunnett T3 post hoc analysis to identify statistically significant differences between the groups. The statistical analysis was obtained using PASW statistic 18 (SPSS, Inc., 2001, Chicago, IL, USA; www.spss.com).

\section{RESULTS}

A total of 46 women were referred by clinic staff to participate in the study. The sociodemographic and reproductive characteristics of the study population were analyzed, and the samples were grouped, based on the cytology results according to cervical cytology, as WP versus CIN2 and CIN3. The 46 cervical scrapes of each patient were processed to identify which type of HPV caused the infection, and the viral load was estimated. We compared the WP samples with the samples with cytological abnormalities.

DNA was extracted, and the identification of HR-HPV and low-risk HPV using HCIIS and PCR-restriction fragment length polymorphism was performed. A total of 31 HPV DNApositive samples displayed infection with HR-HPV (67\%), 41\% were positive for HPV-18, and $39 \%$ were positive to HPV-16; 13 samples (42\%) displayed co-infection with different HPV strains. 
The determination of the HPV viral load after the quantification with quantitative PCR and the normalization of the results (previously showed) present a trend of grouping by type of lesion or cytological lesion in three patient groups: WP, CIN2, and CIN3. Some results exhibited statistical dispersion. The results are illustrated in Figure 1.

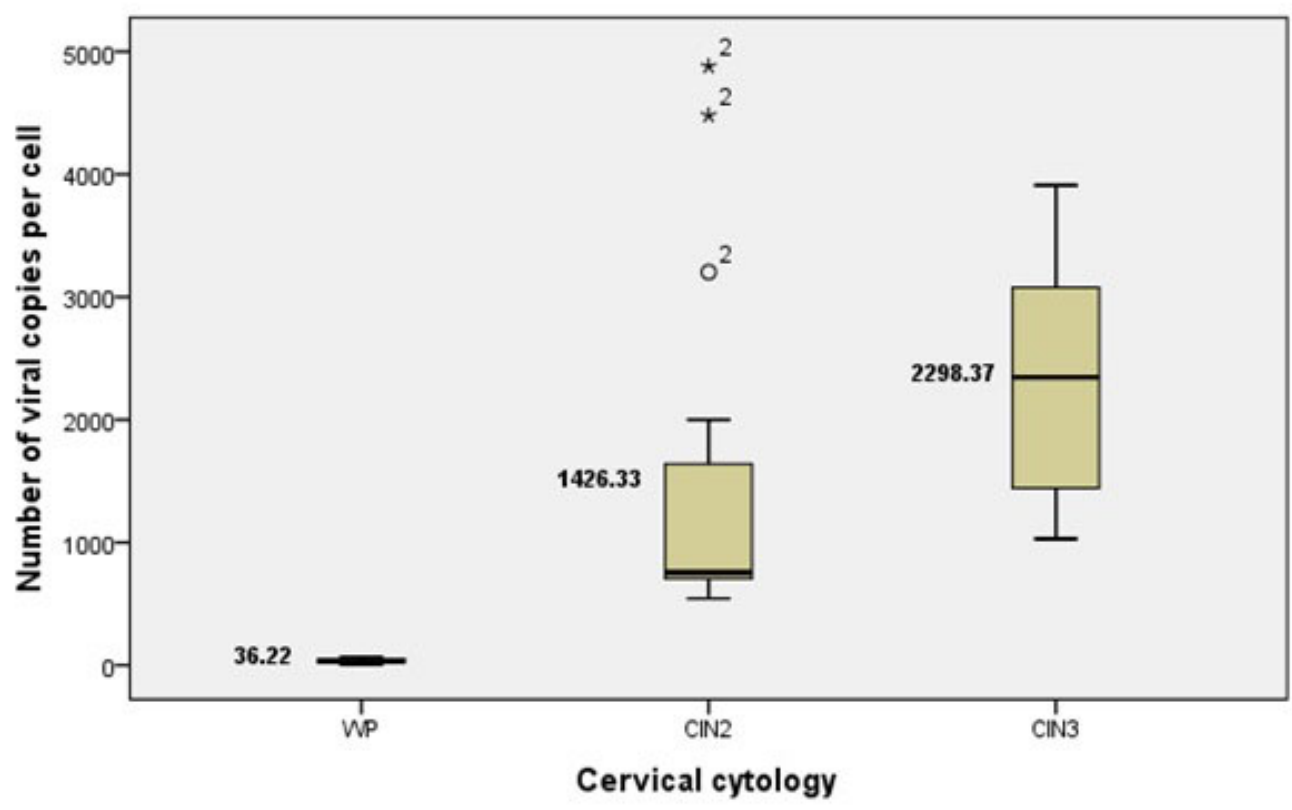

Figure 1. Distribution of all the lectures performed from the qPCR. Patients without cervical pathology (WP) have very small values of HPV viral load per cell and their average is 36.22 virions per cell. The results for the patients with cervical intraepithelial neoplasia grade two (CIN2) and cervical intraepithelial neoplasia grade three (CIN3) showed a similar distribution, their mean average were 1426.33 and 2298.37, respectively; in CIN3 the values of HPV viral load are greater than the results shown for the patients with CIN2. Moreover, the patients with CIN2 or CIN3 present statistical dispersion of the data. $\mathrm{o}^{2}=$ data were above two standard deviations; ${ }^{* 2}=$ data were above three standard deviations.

Means and standard error of the number of HPV viral copies per cell are shown in Table 1. The Levene test $(7.49, \mathrm{P}=0.002)$ was performed, and the null hypothesis of equal variances was rejected, leading us to conclude that a statistical difference existed between the variances. Therefore, we modified the procedures used to eliminate the assumption of equality of variance. One-way analysis of variance presented a significant intergroup difference $(\mathrm{P}=$ 0.000012 ) but no intragroup difference. Because the difference was at the intergroup level and the variances were unequal, the T3 of the Dunnett test demonstrated the differences within these groups. The analysis showed significant differences between WP and CIN2 patients (P $=0.001)$. Moreover, significant difference was found between WP and CIN3 patients $(\mathrm{P}<$ 0.001). The comparison of CIN 2 and CIN3 showed no significant differences ( $99 \%$ of confidence). The results are illustrated in Table 2 . The data obtained showed significant differences in distribution between CIN2-3 and WP. 


Table 1. Mean, standard error (SE) and descriptive statistical data for HPV viral load in patients: WP, CIN2 and
CIN3.
\begin{tabular}{lrrrrrr} 
\\
\hline
\end{tabular}

$\mathrm{WP}=$ without cervical pathology; CIN2 = cervical intraepithelial neoplasia grade $2 ; \mathrm{CIN} 3=$ cervical intraepithelial neoplasia grade 3 .

\begin{tabular}{|c|c|c|c|c|c|c|}
\hline \multirow[t]{2}{*}{ Group (I) } & \multirow[t]{2}{*}{ Group (J) } & \multirow[t]{2}{*}{ Mean differences (I - J) } & \multirow[t]{2}{*}{ SE } & \multirow[t]{2}{*}{ Significance } & \multicolumn{2}{|c|}{ Confidence interval at $99 \%$} \\
\hline & & & & & Lower limit & Superior limit \\
\hline \multirow[t]{2}{*}{ WP } & CIN2 & $-1390.111^{*}$ & 319.605 & 0.001 & -2231.68 & -548.54 \\
\hline & CIN3 & $-2262.146^{*}$ & 202.786 & 0.000 & -2793.07 & -1731.22 \\
\hline \multirow[t]{2}{*}{ CIN2 } & WP & $1390.111 *$ & 319.605 & 0.001 & 548.54 & 2231.68 \\
\hline & CIN3 & -872.035 & 378.382 & 0.082 & -1828.29 & 84.22 \\
\hline \multirow[t]{2}{*}{ CIN3 } & WP & $2262.146 *$ & 202.786 & 0.000 & 1731.22 & 2793.07 \\
\hline & CIN2 & 872.035 & 378.382 & 0.082 & -84.22 & 1828.29 \\
\hline
\end{tabular}

*The differences between the mean values are significant at 0.01 of confidence. $\mathrm{WP}=$ without cervical pathology; CIN2 = cervical intraepithelial neoplasia grade 2; CIN3 = cervical intraepithelial neoplasia grade 3.

\section{DISCUSSION}

Research has shown that HPV viral load is associated with CIN grade (Xu et al., 2009). Reports of the association between viral load and the risk of developing severe CIN suggest that high viral load plays an important role in the development of cancer (Moberg et al., 2005). These results agree with ours, which showed that the increment of HPV viral load corresponded to lesion grade. Viral load was constant along the pathological process, as previously described (McMurray et al., 2001). However, we must consider that the constant number of viruses is within the cell; our assay estimated viruses within and outside of the cell.

The possible use of the HPV viral load to predict lesion grade and the evolution of dysplasia have been proposed by others (Josefsson et al., 2000; Ylitalo et al., 2000; Sun et al., 2001, 2002; Schlecht et al., 2003; Andersson et al., 2005; Fiander et al., 2007; Boulet et al., 2009; Hesselink et al., 2009), and the results have been controversial in that the measurement of HPV viral load is not validated for clinical use and, therefore, the clinical relevance of HPV viral load measurement has not been properly evaluated (Lorincz et al., 2002; Castle et al., 2004; Andersson et al., 2005; Wensveen et al., 2005; Grce et al., 2010). However, HCIIS is a proper method (U.S. Food and Drug Administration approved) for a clinical approach and offers easily reproducible results (Castle et al., 2008). It has also been validated with external evaluations through proficiency testing with HPV surveys offered by the College of American Pathologists. Because HCIIS gives an absolute semi-quantification of viral count, normalization with the number of exfoliated cells must be carried out. The reported association between neoplasm size and viral load may be related to the number of infected cells analyzed, which appears to be increased in samples from patients with widely affected tissue areas. The asso- 
ciation between viral load and the risk of developing cervical cancer may be caused by different standardizations and normalizations of the absolute number of viral copies in a sample as well as by different grouping criteria (i.e., CIN1 vs CIN2 or CIN1 vs CIN2-3). These differences might explain the variability in results among reports. The importance of homologous methods in the normalization of data is clear, and the normalization proposed herein can be used with good approximation to the actual viral load in the samples.

According to our results, $67 \%$ of patients infected with HPV-HR were infected with viral genotypes 16 and $18(80 \%)$, and the patients with co-infection had one or both of these genotypes (data not show). Further, we observed a significant increase between the WP means compared with those of CIN2 and CIN3 samples (WP vs CIN2, P = 0.001; WP vs CIN3, P $<0.000,99 \%$ confidence), but no significant difference was observed in a comparison of the degrees of lesions. Figure 1 shows a dispersion of values in the CIN2 samples in which some samples displayed an even greater number of viral copies per cell than that in CIN3. This result can be explained by the frequent misclassification of lesion grade in samples (Briolat et al., 2007). The CIN2 grade has the highest level of misclassification owing to variability in interpretation by the observer; CIN2 can represent the spectrum of late CIN1, CIN2, or early CIN3 (Briolat et al., 2007; Xi et al., 2008); true CIN2 is thought of as an early phenotype of high-grade CIN, a true cervical precancerous lesion (Einstein, 2008).

The results obtained in this study should be interpreted with some caution mainly because the number of samples is low.

The results led us to propose that HPV viral load can serve as a biomarker for lesions and may be useful for predicting the evolution of CIN. The detection of HR-HPV DNA can be a routine screening tool combined with or even instead of cytology. Additionally, we consider that a patient with Pap test results of undetermined significance and a viral load above 1000 viral copies per cell will present a severe dysplasia and, therefore, a value below 1000 viral copies per cell could lead to a CIN1, with the possibility of spontaneous reversion or even no cervical lesion.

\section{REFERENCES}

Andersson S, Safari H, Mints M, Lewensohn-Fuchs I, et al. (2005). Type distribution, viral load and integration status of high-risk human papillomaviruses in pre-stages of cervical cancer (CIN). Br. J. Cancer 92: 2195-2200.

Boulet GA, Benoy IH, Depuydt CE, Horvath CA, et al. (2009). Human papillomavirus 16 load and E2/E6 ratio in HPV16positive women: biomarkers for cervical intraepithelial neoplasia $\geq 2$ in a liquid-based cytology setting? Cancer Epidemiol. Biomarkers Prev. 18: 2992-2999.

Briolat J, Dalstein V, Saunier M, Joseph K, et al. (2007). HPV prevalence, viral load and physical state of HPV-16 in cervical smears of patients with different grades of CIN. Int. J. Cancer 121: 2198-2204.

Cain JM and Howett MK (2000). Preventing cervical cancer. Science 288: 1753-1755.

Castle PE, Schiffman M and Wheeler CM (2004). Hybrid capture 2 viral load and the 2-year cumulative risk of cervical intraepithelial neoplasia grade 3 or cancer. Am. J. Obstet. Gynecol. 191: 1590-1597.

Castle PE, Schiffman M, Scott DR, Sherman ME, et al. (2005). Semiquantitative human papillomavirus type 16 viral load and the prospective risk of cervical precancer and cancer. Cancer Epidemiol. Biomarkers Prev. 14: 1311-1314.

Castle PE, Solomon D, Wheeler CM, Gravitt PE, et al. (2008). Human papillomavirus genotype specificity of hybrid capture 2. J. Clin. Microbiol. 46: 2595-2604.

Clavel C, Masure M, Bory JP, Putaud I, et al. (2001). Human papillomavirus testing in primary screening for the detection of high-grade cervical lesions: a study of 7932 women. Br. J. Cancer 84: 1616-1623.

Einstein MH (2008). Acquired immune response to oncogenic human papillomavirus associated with prophylactic cervical cancer vaccines. Cancer Immunol. Immunother. 57: 443-451.

Fiander AN, Hart KW, Hibbitts SJ, Rieck GC, et al. (2007). Variation in human papillomavirus type-16 viral load within 
different histological grades of cervical neoplasia. J. Med. Virol. 79: 1366-1369.

Grce M, Matovina M, Milutin-Gasperov N and Sabol I (2010). Advances in cervical cancer control and future perspectives. Coll. Antropol. 34: 731-736.

Hesselink AT, Berkhof J, Heideman DA, Bulkmans NW, et al. (2009). High-risk human papillomavirus DNA load in a population-based cervical screening cohort in relation to the detection of high-grade cervical intraepithelial neoplasia and cervical cancer. Int. J. Cancer 124: 381-386.

Ho GY, Burk RD, Klein S, Kadish AS, et al. (1995). Persistent genital human papillomavirus infection as a risk factor for persistent cervical dysplasia. J. Natl. Cancer Inst. 87: 1365-1371.

Javier RT and Butel JS (2008). The history of tumor virology. Cancer Res. 68: 7693-7706.

Josefsson AM, Magnusson PK, Ylitalo N, Sorensen P, et al. (2000). Viral load of human papilloma virus 16 as a determinant for development of cervical carcinoma in situ: a nested case-control study. Lancet 355: 2189-2193.

Lillo FB and Uberti-Foppa C (2006). Human papillomavirus viral load: a possible marker for cervical disease in HIVinfected women. J. Antimicrob. Chemother. 57: 810-814.

Lorincz AT, Castle PE, Sherman ME, Scott DR, et al. (2002). Viral load of human papillomavirus and risk of CIN3 or cervical cancer. Lancet 360: 228-229.

McMurray HR, Nguyen D, Westbrook TF and McAnce DJ (2001). Biology of human papillomaviruses. Int. J. Exp. Pathol. 82: 15-33.

Mendizabal-Ruiz AP, Morales JA, Ramirez-Jirano LJ, Padilla-Rosas M, et al. (2009). Low frequency of human papillomavirus DNA in breast cancer tissue. Breast Cancer Res. Treat. 114: 189-194.

Moberg M, Gustavsson I, Wilander E and Gyllensten U (2005). High viral loads of human papillomavirus predict risk of invasive cervical carcinoma. Br. J. Cancer 92: 891-894.

Nobbenhuis MA, Walboomers JM, Helmerhorst TJ, Rozendaal L, et al. (1999). Relation of human papillomavirus status to cervical lesions and consequences for cervical-cancer screening: a prospective study. Lancet 354: 20-25.

Nobbenhuis MA, Helmerhorst TJ, van den Brule AJ, Rozendaal L, et al. (2001). Cytological regression and clearance of high-risk human papillomavirus in women with an abnormal cervical smear. Lancet 358: 1782-1783.

Remmink AJ, Walboomers JM, Helmerhorst TJ, Voorhorst FJ, et al. (1995). The presence of persistent high-risk HPV genotypes in dysplastic cervical lesions is associated with progressive disease: natural history up to 36 months. Int. J. Cancer 61: 306-311.

Sargent A, Bailey A, Turner A, Almonte M, et al. (2010). Optimal threshold for a positive hybrid capture 2 test for detection of human papillomavirus: data from the ARTISTIC trial. J. Clin. Microbiol. 48: 554-558.

Schlecht NF, Trevisan A, Duarte-Franco E, Rohan TE, et al. (2003). Viral load as a predictor of the risk of cervical intraepithelial neoplasia. Int. J. Cancer 103: 519-524.

Seaman WT, Andrews E, Couch M, Kojic EM, et al. (2010). Detection and quantitation of HPV in genital and oral tissues and fluids by real time PCR. Virol. J. 7: 194.

Sun CA, Lai HC, Chang CC, Neih S, et al. (2001). The significance of human papillomavirus viral load in prediction of histologic severity and size of squamous intraepithelial lesions of uterine cervix. Gynecol. Oncol. 83: 95-99.

Sun CA, Liu JF, Wu DM, Nieh S, et al. (2002). Viral load of high-risk human papillomavirus in cervical squamous intraepithelial lesions. Int. J. Gynaecol. Obstet. 76: 41-47.

Wensveen CW, Kagie MJ, Nagelkerke NJ, Veldhuizen RW, et al. (2005). Can viral load, semi-quantitatively evaluated, of human papillomavirus predict cytological or histological outcome in women with atypical squamous or glandular cells of undetermined significance cytology? Eur. J. Gynaecol. Oncol. 26: 393-397.

Winer RL, Lee SK, Hughes JP, Adam DE, et al. (2003). Genital human papillomavirus infection: incidence and risk factors in a cohort of female university students. Am. J. Epidemiol. 157: 218-226.

Xi LF, Kiviat NB, Galloway DA, Zhou XH, et al. (2008). Effect of cervical cytologic status on the association between human papillomavirus type 16 DNA load and the risk of cervical intraepithelial neoplasia grade 3. J. Infect. Dis. 198: 324-331.

Xu Y, Dotto J, Hui Y, Lawton K, et al. (2009). High grade cervical intraepithelial neoplasia and viral load of high-risk human papillomavirus: significant correlations in patients of 22 years old or younger. Int. J. Clin. Exp. Pathol. 2: 169-175.

Ylitalo N, Sorensen P, Josefsson AM, Magnusson PK, et al. (2000). Consistent high viral load of human papillomavirus 16 and risk of cervical carcinoma in situ: a nested case-control study. Lancet 355: 2194-2198.

Zielinski GD, Snijders PJ, Rozendaal L, Voorhorst FJ, et al. (2001). HPV presence precedes abnormal cytology in women developing cervical cancer and signals false negative smears. Br. J. Cancer 85: 398-404. 